\title{
ICF-Based Analysis of Communication Disorders in Dementia of Alzheimer's Type
}

\author{
Mohamad Basheer Badarunisa ${ }^{a}$ Daly Sebastian ${ }^{b}$ \\ Raghunath Rao Rangasayee $^{\mathrm{b}} \quad$ Baby Kala $^{\mathrm{a}}$

\begin{abstract}
${ }^{a}$ Institute of Speech and Hearing, Marthoma College of Special Education, Kerala University of Health Sciences, Badiyadka, and 'bepartment of Audiology and Speech Language Pathology, Dr. SR Chandrasekhar Institute of Speech and Hearing, Bangalore, India
\end{abstract}

\author{
Key Words \\ International Classification of Functions · Functionality · Dementia of Alzheimer's type · \\ Cognitive communication
}

\begin{abstract}
Purpose: Dementia of Alzheimer's type (DAT) is a major cognitive communication disorder. The present study attempted to analyse communication disorders in DAT in the International Classification of Functions (ICF) framework. The study investigated the impact of the severity of communication disorders in persons with DAT on activity participation and environment components of the ICF. Method: Thirty bilingual individuals with DAT in the age range of 6588 years were classified into three groups of mild, moderate and severe degree of dementia. Forty-three items of the American Speech-Language-Hearing Association Functional Assessment of Communication Skills for Adults (ASHA FACS) were linked to the ICF framework. A few additional items were also added for a complete profiling of DAT. A total of 50 (ASHA FACS + ICF) items were rated and administered for the purpose of the study. Results: The study revealed a disproportionate impact of the severity of DAT on activity participation and environment components of the ICF. Conclusion: The present study investigated the utility of the ICF framework for profiling the functionality of persons with DAT. This profiling highlighted the need for ensuring effective communication and quality of life in the DAT population.
\end{abstract}


The International Classification of Functions (ICF) provides an interactive, individualized and personalized model for the conceptualization, measurement and classification of functioning [1]. The ICF is a revised version of the International Classification of Impairment Disability and Handicap, which moves beyond the consequence of disease approach (i.e., impairment, disability and handicap) and highlights functioning as a component of health. Thus, the ICF is an active measure of the overall functionality of an individual and indicates the impact of a chronic health condition and its effect on various life domains. The aim of the current study is to investigate the impact of dementia of Alzheimer's type (DAT) on the functionality of affected individuals by using the ICF framework. ICF does not define dementia, but provides a framework for understanding and measuring the functional outcomes of dementia in terms of three components: body functions and structures, activities and participation, and environmental factors (Appendix I). According to the International Classification of Disorders (ICD) and the Diagnostic Static Manual (DSM), the core element for the diagnosis of dementia is cognitive impairment 'sufficient to impair personal activities of daily living' or which causes significant social and occupational impairments. The first part of the core element, cognitive impairments of dementia, is profiled under the body structure and functions domain of the ICF. Activities and participation component addresses the second part of the core element. The environment component codes are typically used for describing facilitators and barriers in the environment of persons with dementia.

Cognitive communication disorders are one of the major characteristic of DAT, and communication may be impaired from the first stage of dementia [2-4]. Memory and other cognitive decline result in deficits in comprehension and expression domains of language [5]. Severe deficits are reported in naming, describing, writing, and pragmatics [6]. Hopper [7] categorized body functions related to the cognitive communication disorders in DAT under cognition, language, and behavioural function (global mental functions, b110-b139; specific mental functions, b140-b189) domains of the ICF, giving a clear picture about the severity of the cognitive communication disorder in DAT based on its progression and different stages.

Functional communication, defined by the American Speech-Language-Hearing Association (ASHA) [8] as the ability to receive or convey a message as well as to communicate effectively and independently in a natural environment regardless of the mode of communication, is a major measure of dementia. The Functional Linguistic Communication Inventory [9] is a standardized measure that includes items designed for individuals with moderate to severe dementia. This inventory incorporates the components of body functions, activity and participation. Disability Assessment for Dementia [10] and Independent Living Scales [11] are other tools used to assess the functionality of persons with dementia. Carvalho et al. [12] used the American Speech-Language-Hearing Association Functional Assessment of Communication Skills for Adults (ASHA FACS) [13] to profile and compare functional communication in individuals with frontotemporal dementia and DAT. However, these measures are also not sufficient enough to profile the complete functionality of individuals with DAT based on the impact of disorder in various life domains. Linking rules have been adopted to harmonize the existing functional communication tools into the ICF framework to give a clear picture about the activity limitations and participation restriction of persons with DAT. Hopper [7] described the ICF codes which are applicable for dementia. Activity and participation limitations in Alzheimer's disease include limitations in initiating (d3500), maintaining (d3501), and terminating (d3502) conversations with others, and completing tasks that involve the use of language to read, write, speak, and understand others in everyday activities [e.g., using the telephone (d3600), reading the newspaper or a recipe (d325), and understanding directions for medication use (d325)].

The third domain of the ICF framework identifies the environmental barriers and facilitators. The communication environment plays a crucial role in the management of persons 
with DAT. For example, caregivers' failure to use simple sentences while talking to a person with DAT, leads to difficulty in comprehending the spoken message. Modification of the communication environment is a major management approach for cognitive communication deterioration in dementia. Therefore, identification of barriers and facilitators is relevant for modifying the communication environment of persons with dementia.

Since DAT has a devastating impact on various life domains of individuals, the current study attempted to profile the overall functionality of persons with dementia on the ICF framework. The main focus of existing clinical tools is on the severity of cognitive deterioration in DAT rather than its impact on functionality of the individual. The available tools do not address the barriers in the communication environment of the person with DAT.

The aims of the current study are: (1) to profile the communication-related activity and participation in persons with DAT by using the ICF framework; (2) to identify the barriers in the communication environment of persons with DAT by using the ICF framework, and (3) to study the impact of the severity of DAT on activity participation and the environment component of the ICF framework.

\section{Method}

\section{Participants}

Thirty bilingual (English-Malayalam) individuals (16 males and 14 females) diagnosed with Alzheimer's disease in the age range of 65-88 years (mean 77.4, SD 6.6) participated in the study. Participants were diagnosed by a medical team including a neurologist, a neuropsychiatrist and experts in geriatrics. On the day of data collection, participants were assessed using the Mini-Mental State Examination [14] and Clinical Dementia Rating (CDR) Scale [15]. Based on the CDR scores, participants were grouped into mild $(n=9)$, moderate $(n=12)$ and severe $(n=9)$ degree of dementia. Individuals with evidence for other neurological disorders such as traumatic brain injury, stroke, hydrocephalus, and encephalopathy as well as psychiatric disorders such as major depression or schizophrenia were excluded from participation. Participants were taken from dementia care centres, home visits and old age homes. Informed consent was taken from participants as well as from their significant others. The study did not include any invasive procedures, and all procedures were strictly adhered to ethical considerations.

\section{Tools Used}

The ASHA FACS [13] was selected as the functional communication tool. ASHA FACS addresses functional communication across four domains: Social Communication; Communication of Basic Needs; Reading, Writing, Number Concepts, and Daily Planning. Measurement of the 43 functional communication items is based on a 7-point scale, where $1=$ does not do, $2=$ needs constant assistance to perform a communicative behaviour, $3=$ needs assistance very frequently, 4 = needs moderate assistance, 5 = needs assistance occasionally, 6 = rarely needs assistance, and 7 = totally independent to perform the communication behaviour. Information about the 43 items was obtained by direct observation, client and caretaker reporting. The scale can be administered in approximately $20 \mathrm{~min}$. Although it is a general tool to assess the functional communication in adults, some studies attempted to classify the functional communication of adults with neurogenic disorders. Hughes and Orange [16] tried to profile functional communication in traumatic brain injury into the WHO ICF framework by mapping the ASHA FACS items. The current study made a similar attempt in the DAT population by using ASHA FACS as a tool to link with the various subdomains of the ICF framework. 
Badarunisa et al.: ICF-Based Analysis of Communication Disorders in Dementia of Alzheimer's Type

\section{ASHA FACS Items and the ICF Framework}

Each item in ASHA FACS was linked to the ICF framework by assigning an ICF code. Linking was done based on the existing guidelines $[17,18]$. Hopper [7] has provided the codes which are specific to dementia. Those codes were also considered during the linking process. Judge A was involved in the field testing phase of the ICF in India and had 10 years of work experience with the ICF, and judge B had 4 years of practical experience with the framework. Interrater agreement was statistically verified by using Cohen's kappa $(\kappa=0.72)$. The severity rating scales used (CDR and the Mini-Mental State Examination) were capable of addressing the impairment and severity of various body functions which are related to DAT. Therefore, the current study excluded the body structures and function component from its main goal. The main focus of the study was on activity, participation and environment domains.

Appendix III lists codes assigned to each ASHA FACS item. All 43 ASHA FACS items matched with the components under 'functioning' and 'disability'. Codes were selected from the various subdomains of the activity and participation domain. Selected ICF domains were communication, learning and applying knowledge, interpersonal interactions and relationship, major life areas, domestic life and general task demands. Thirty-two of the 43 ASHA FACS items were linked to various items under a communication subdomain. Three items were included under learning and applying knowledge. Five items were assigned codes under general task demands. Two items were linked with items under interpersonal interactions and relationships. Item number 37 was linked with a code under the major life area subdomain. Five additional items were also added from ICF subdomains such as domestic life (d6200), interpersonal interactions and relationships (d7104, d7701), domestic life (d6600) as well as community, social, and civic life (d9205). Details are given in Appendix IV. To address the specific communication barriers in environment, two items from the environment component of the ICF were also included. Codes under the environment domain were added from the products and technology subsection (e1250) and the support and relationship subdomain (e310/e340). All 50 items (ASHA FACS + ICF) were identified as applicable to Alzheimer's disease by five speech language pathologists with 6 years of experience. Interrater reliability was checked by using the weighted kappa analysis $(\kappa w=7.4)$. Distribution of 50 selected items are given in Appendix II.

\section{Results}

Thirty bilingual participants (English-Malayalam) aged 65-88 years (16 males and 14 females) who met the selection criteria and whose responses (including caretaker) to the questionnaire were complete in all aspects were analysed.

Table 1 shows the distribution of the number of participants with various levels of activity limitations and participation restrictions. It can be seen in table 1 that 10 individuals had moderate issues in the communication component and 20 individuals had severe issues. In the subdomain of learning and applying knowledge, 3 individuals had mild issues, 8 had moderate issues and 19 had severe issues. In the interpersonal interactions and relationship domain, 5 participants had mild level problems, 10 had moderate level issues and 15 had severe level issues. Two individuals had mild level issues in the major life areas subdomain, 7 had moderate level issues and 21 had severe issues. Eighteen participants had severe issues in the general task demands subdomain. Nine individuals had moderate issues and 3 had mild issues in the same subdomain. Participants in the subdomain of domestic life had issues ranging from mild to severe levels. Sixteen participants had severe difficulties, 9 had moderate difficulties and 5 had mild difficulties. Participants had various levels of difficulties in community, social, and civic life. 
Table 1. Distribution of the number of participants with various levels of activity limitations and participation restrictions

\begin{tabular}{lcrrrrrr}
\hline $\begin{array}{l}\text { Level of activity limitation and } \\
\text { participation restriction }\end{array}$ & Communication & LAK & IIR & MLA & GTD & DL & CSCL \\
\hline Mild & - & 3 & 5 & 2 & 3 & 5 & 4 \\
Moderate & 10 & 8 & 10 & 7 & 9 & 9 & 8 \\
Severe & 20 & 19 & 15 & 21 & 18 & 16 & 18 \\
\hline
\end{tabular}

LAK = Learning and applying knowledge; IRR = interpersonal interactions and relationship; MLA = major life areas; GTD = general task demands; DL = domestic life; CSCL = community, social, and civic life.

Table 2. Kruskal-Wallis comparison of the activity and participation component in persons with mild, moderate and severe DAT

Table 3. Kruskal-Wallis comparison of the environment component in persons with mild, moderate and severe DAT

\begin{tabular}{lrllll}
\hline Groups & $\mathrm{n}$ & Mean rank & \multicolumn{3}{l}{ Test statistics (Kruskal-Wallis) } \\
\cline { 4 - 6 } & & & d.f. & $\chi^{2}$ test & p value \\
\hline Mild & 9 & 12.11 & 2 & 3.599 & 0.165 \\
Moderate & 12 & 14.88 & & & \\
Severe & 9 & 19.72 & & & \\
\hline
\end{tabular}

d.f. = Degree of freedom .

\begin{tabular}{lrrlll}
\hline Groups & $\mathrm{n}$ & Mean rank & \multicolumn{3}{l}{ Test statistics (Kruskal-Wallis) } \\
\cline { 3 - 6 } & & & d.f. & $\chi^{2}$ test & p value \\
\hline Mild & 9 & 9.78 & 2 & 7.621 & $0.022^{*}$ \\
Moderate & 12 & 15.92 & & & \\
Severe & 9 & 20.67 & & & \\
\hline
\end{tabular}

d.f. $=$ Degree of freedom. ${ }^{*}$ Significant $\mathrm{p}$ value.

\section{Comparison of Mild, Moderate and Severe DAT Groups on the Activity Participation}

Component of the ICF

The Kruskal-Wallis test results revealed that there is no significant difference $\left(\chi^{2}=3.599\right.$, $\mathrm{p}=0.165$ ) between the mild, moderate and severe DAT groups in the activity and participation components of the ICF. Therefore, post hoc evaluation was not carried out for this component. Results are suggestive of an equal impact on the ICF activity and participation domain, irrespective of the severity of DAT (table 2).

Comparison of Mild, Moderate and Severe DAT Groups on the Environment Component of the ICF

The comparison of three groups on the environmental component revealed a significant difference in the Kruskal-Wallis test $\left(\chi^{2}=7.621, p=0.022\right)$ (table 3).

Since the Kruskal-Wallis test showed a significant difference, a post hoc evaluation was carried out by Tukey's HSD test. Multiple comparison by post hoc analysis revealed a signif- 
Badarunisa et al.: ICF-Based Analysis of Communication Disorders in Dementia of Alzheimer's Type

Table 4. Post hoc analysis (Tukey's HSD) of the environment component in persons with mild, moderate and severe DAT

\begin{tabular}{llcll}
\hline I & J & Mean difference (I-J) & SE & p value \\
\hline Mild & Moderate & -9.194 & 4.674 & 0.140 \\
& Severe & -15.777 & 4.997 & $0.011^{*}$ \\
\hline \multirow{2}{*}{ Moderate } & Mild & 9.194 & 4.674 & 0.140 \\
& Severe & -6.583 & 4.674 & 0.351 \\
\hline \multirow{2}{*}{ Severe } & Mild & 15.777 & 4.997 & $0.011^{*}$ \\
& Moderate & 6.583 & 4.674 & 0.351 \\
\hline
\end{tabular}

* Significant p value.

icant mean difference between mild and severe DAT groups $(p=0.011)$ on the environment component of the ICF. At the same time, multiple comparison indicated that there was no significant difference between the mild and moderate DAT groups $(\mathrm{p}=0.140)$ as well as in the moderate and severe groups $(\mathrm{p}=0.351)$ (table 4$)$.

\section{Discussion}

\section{Communication-Related Activity Limitations and Participation Restrictions in DAT}

Activity limitations and participation restrictions due to impairment in body functions and structure are highlighted as major criteria for the diagnosis of dementia. Memory and other cognitive impairments result in marked problems with social and occupational functioning. As a result of the interaction between the impairments of DAT and contextual factors, all individuals with DAT experience communication-related activity limitations and participation restrictions [19]. Therefore, it was crucial to study the impact of dementia on multiple functional domains of individuals. Assessment of multiple domains of functions is essential to determine abilities as well as potential goals and outcomes of intervention programs [20]. Hence, the current study included 48 items under various subdomains of activity and participation components of the ICF. It addressed communication-related activity limitation and participation restrictions under various subdomains such as communication, learning and applying knowledge, interpersonal interactions and relationship, major life areas, domestic life, general task demands as well as community, social, and civic life.

The results of the present study revealed that there was no significant difference across the mild, moderate and severe DAT groups on the activity and participation component of the ICF. Irrespective of severity, all 30 participants had significant activity limitations and participation restrictions. Hence, it can be inferred from the current study that the severity of dementia is not a factor that predicts the functionality of the individual. In other words, even a mild degree of dementia can cause severe activity limitation and participation restriction in communication-related functional domains. It can be inferred from the study that the severity rating tools are insufficient enough to profile the activity limitation and participation restriction in DAT. Functionality assessment is crucial for the management of DAT. Machado [21] investigated the influence of participation at a rehabilitation centre on the quality of life and Alzheimer's disease. They concluded that combining pharmacological treatment with psychosocial intervention might prove to be an effective strategy to enhance the quality of life of persons with DAT. Therefore, the current study highlights the utility of the ICF framework in documentation of activity limitations and participation restrictions to set therapy goals of persons with DAT. 
The Impact of the Severity of Dementia on the Environment Component of the ICF

Post hoc analysis by Tukey's HSD multiple comparison revealed that there is a significant difference in the environmental barriers for communication across the mild, moderate and severe DAT groups. The difference was significant between the mild and severe groups. The mean difference suggested a continuum across the three different groups (mild < moderate $<$ severe). The results are suggestive of minimal environmental barriers for the mild group when compared to the moderate and severe groups. This finding was consistent with those observations which indicated that persons with mild DAT benefit from strategies to improve memory, and they continue to live relatively independent lives with a minimum of assistance [22]. Moderate and severe DAT populations required substantial support from their caregivers. Participants in the present study obtained good environmental support in their general care aspects. However, support from the caregiver or family members was minimal for communication enhancement. Byrne and Orange [19] identified caregivers' lack of knowledge about how to communicate with older adults with DAT as the major barrier to optimize functioning. In the present study, this can also be a major reason for the reported environmental barriers in functional communication. Family members and caregivers were not aware of the various communication strategies that could be used in persons with DAT. Zientz et al. [23] emphasized caregiver education as a part of the evidence-based practice recommendations for dementia. Robinson et al. [24] found that inclusion of multiple caregivers in cognitive behavioural therapy for treating anxiety in persons with dementia is feasible and may be beneficial in maximizing treatment gains and increasing the family's participation in therapy. Caregiver-focused intervention is essential for the effective incorporation of communication strategies in the various phases of Alzheimer's disease. Thus, the current study emphasizes the need for educating the caregivers to become a facilitator in functional communication.

\section{Implications of the Study}

According to Kinsella and Phillips [25], individuals with dementia-associated communication problems are the fastest growing clinical population. The most common dementiaassociated diseases are progressive in nature and in need of appropriate services that will benefit the individual and maximize cognitive-communication functioning at all stages of the disease process. The current study attempted to profile the communication-related activity limitations, participation restrictions and environmental barriers in persons with DAT. It highlighted the implication of the ICF in profiling the overall functionality of the individuals with DAT irrespective of the severity of the disorder. This study has implications for making a management plan oriented towards functionality of persons with DAT. Furthermore, it highlighted the need towards caregiver-oriented communication management of individuals. The study will have implications for deciding the occupational status (back to work or continuing in work) of persons with dementia. The ASHA [26] mandates the role of the speech language pathologist in the identification, assessment, intervention, counselling, collaboration, case management, education, advocacy and research of persons with DAT. Since the current study focused on the overall functionality of the individual, it will be useful for the speech language pathologists to address the specific goals in the DAT population on a broader perspective. Even though we did not address the outcome measurement, future studies can focus on the utility of a similar framework to document the functionality before and after treatment. Future studies extending the same methods for other adult communication disorders should also be conducted. 
Badarunisa et al.: ICF-Based Analysis of Communication Disorders in Dementia of Alzheimer's Type

\section{Conclusion}

The present study aimed to profile DAT-based communication disorders on the ICF framework and investigated the influence of the severity of DAT on various ICF components. ASHA FACS items were linked to various ICF domains. Additional items were also added to obtain a complete picture of communication-related functionality of the individuals. The results highlighted the unique feature of the ICF in profiling the activity limitations and participation restrictions of persons with DAT irrespective of the severity. It also indicated a need for modification of the communication environment and caregiver-oriented intervention for persons with DAT. Thus, the interactive ICF model is highly useful for profiling a multifaceted condition like DAT in an individualized and personalized way. The study has implication for facilitating communication-related quality of life in DAT population.

\section{Appendix I}

Body functions are the physiological functions of body systems (including psychological functions).

Body structures are anatomical parts of the body such as organs, limbs and their components.

Impairments are problems in body function and structure such as significant deviation or loss.

Activity is the execution of a task or action by an individual.

Participation is involvement in a life situation.

Activity limitations are difficulties an individual may have in executing activities.

Participation restrictions are problems an individual may experience in involvement in life situations.

Environmental factors make up the physical, social and attitudinal environment in which individuals live and conduct their lives. These are either barriers to or facilitators of the person's functioning.

Appendix II: Item Distribution of ASHA FACS in the Body Function, Activities and Participation and Environment Components of the ICF

\begin{tabular}{llcc}
\hline Component & Domains & ASHA-FACS & Items added \\
\hline Activities & Community, social, and civic life & - & 1 \\
and & Domestic life & - & 2 \\
participation & Applying knowledge and learning & 3 & 2 \\
& Interpersonal interactions and relations & 2 & \\
& General tasks and demands & 5 & \\
& Communication & 32 & 5 \\
& Major life areas & 1 & 1 \\
\cline { 2 - 3 } & Total & 43 & 1 \\
\hline Environment & Products and technology & - & 2 \\
& Support and relationship & - & 50 \\
\cline { 2 - 4 } & Total & & \\
\hline
\end{tabular}




\section{Appendix III: ICF Codes Assigned to Items in ASHA FACS (Activities and Participation)}

\section{ASHA FACS items}

I. Social communication

1. Refers to familiar individuals by name

2. Requests information of others

3. Explains how to do something

4. Expresses agreement/disagreement

5. Exchanges information on the phone

6. Participates in group conversation

7. Answers yes/no questions

8. Follows simple verbal directions

9. Understands non-literal meaning and inference

10. Smiles or laughs at lighthearted comments

11. Understands non-literal meaning and inference

12. Understands conversations when they occur in noise

13. Understands what's heard on TV and radio

14. Understands facial expressions

15. Understands the tone of voice

16. Initiates communication with other individuals

17. Adds new information on a topic in conversation

18. Changes topics in conversation

19. Adjusts to a change in a topic in conversation

20. Recognizes his/her own communication errors

21. Corrects his/her own communication errors

\section{Communication of basic needs}

22. Recognizes familiar faces

23. Recognizes familiar voices

24. Makes strong likes or dislikes known

25. Expresses feelings

26. Requests help when necessary

27. Makes needs or wants known

28. Responds in an emergency

\section{Reading, writing, number concepts}

29. Understands simple signs

30. Uses common reference materials

31. Follows written directions

32. Understands basic printed material

33. Prints/writes/types name

34. Fills out short forms

35. Writes messages

36. Understands signs with numbers

37. Makes basic money transactions

38. Understands simple units of measurement d3151

communicating with - receiving - general signs and symbols, communication

$\mathrm{d} 330$

d330

d335

d177

d3600

d3551

d310

d160 focusing attention, learning and applying knowledge

d110, watching, listening, purposeful sensory experience, learning d115 and applying knowledge

d3150 communicating with - receiving - body gestures, communication

d 310 communicating with - receiving - spoken messages, communication

d3500 starting a conversation, conversation, communication

d3501 sustaining a conversation, conversation, communication

respect and warmth in relationships, general interpersonal interactions, interpersonal interactions and relationship

speaking, body language, communication

d325 communicating with - receiving - written messages

d345 writing messages, communication

d325 communicating with - receiving - written messages, communication

d860 basic economic transactions, major life areas

d2303 managing one's own activity level, carrying out daily routine, general tasks and demands 
Badarunisa et al.: ICF-Based Analysis of Communication Disorders in Dementia of

42. Uses a calendar for time-related activities

\section{Appendix IV: Additional ICF Items with Their Codes as Applicable to Dementia}

\begin{tabular}{|c|c|c|c|}
\hline Item & ICF code & Item description & Category/domain/component \\
\hline 1. Shopping & d6200 & domestic life & $\begin{array}{l}\text { acquisition of necessities, activities and } \\
\text { participation }\end{array}$ \\
\hline 2. Social cues in relationships & d7104 & $\begin{array}{l}\text { interpersonal interac- } \\
\text { tions and relati- } \\
\text { onships }\end{array}$ & $\begin{array}{l}\text { basic interpersonal interaction, general } \\
\text { interpersonal interactions, activities } \\
\text { and participation }\end{array}$ \\
\hline $\begin{array}{l}\text { 3. Stress on relationships with family } \\
\text { members and friends due to the inability } \\
\text { to communicate properly }\end{array}$ & $\begin{array}{l}\text { d7701/ } \\
\text { d7500 }\end{array}$ & $\begin{array}{l}\text { intimate relationship/ } \\
\text { informal social relati- } \\
\text { onship }\end{array}$ & $\begin{array}{l}\text { spousal relationships/informal } \\
\text { relationships with friends } \\
\text { particular interpersonal relationships, } \\
\text { interpersonal interactions and } \\
\text { relationships, interpersonal } \\
\text { relationships, activities and } \\
\text { participation }\end{array}$ \\
\hline $\begin{array}{l}\text { 4. Impact of memory loss and communi- } \\
\text { cation difficulties on job or household } \\
\text { responsibilities }\end{array}$ & d6600 & domestic life & $\begin{array}{l}\text { assisting others with self-care } \\
\text { assisting others } \\
\text { caring for household objects and } \\
\text { assisting others } \\
\text { domestic life/activities and } \\
\text { participation }\end{array}$ \\
\hline $\begin{array}{l}\text { 5. Impact of memory loss and } \\
\text { communication difficulties on ability to } \\
\text { enjoy your social activities such as going } \\
\text { out to dinner, to the movies, religious } \\
\text { activities, etc. }\end{array}$ & d9205 & socializing & $\begin{array}{l}\text { community, social, civic activities and } \\
\text { participation }\end{array}$ \\
\hline $\begin{array}{l}\text { 6. Availability communication devices like } \\
\text { telephones, mobile phones and } \\
\text { computers or tablets to aid person with } \\
\text { dementia }\end{array}$ & e1250 & $\begin{array}{l}\text { general products and } \\
\text { technology for } \\
\text { communication } \\
\text { equipment }\end{array}$ & products and technology, environment \\
\hline $\begin{array}{l}\text { 7. Support strategies from environment to } \\
\text { prevent communication breakdown }\end{array}$ & $\begin{array}{l}\text { e310/ } \\
\text { e340 }\end{array}$ & $\begin{array}{l}\text { immediate family/ } \\
\text { caregiver }\end{array}$ & support and relationship, environment \\
\hline
\end{tabular}




\section{References}

1 World Health Organization: ICF: International Classification of Functioning, Disability and Health. Geneva World Health Organization, 2001.

-2 Bayles K: Effects of working memory deficits on the communicative functioning of Alzheimer's dementia patients. J Commun Disord 2003;36:209-219.

-3 Forbes-McKay KE, Venneri A: Detecting subtle spontaneous language decline in early Alzheimer's disease with a picture description task. Neurol Sci 2005;26:243-254.

4 Mansur LL, Carthery MT, Caramelli P, Nitrini R: Linguagem e cognição na doença de Alzheimer (Language and cognition in Alzheimer's disease). Psicol Reflex Crit 2005;18:300-307.

5 Bayles KA, Tomoeda CK, Trosset MW: Relation of linguistic communication abilities of Alzheimer's patients to stage of disease. Brain Lang 1992;42:454-472.

6 Bayles KA, Tomoeda CK, Cruz RG, Mahendra N: Communication abilities of individuals with late-stage Alzheimer disease. Alzheimer Dis Assoc Disord 2000;14:176-181.

7 Hopper T: The ICF and dementia. Semin Speech Lang 2007;28:273-282.

8 American Speech-Language-Hearing Association: Advisory report on functional communication measures project. Rockville, American Speech-Language-Hearing Association, 1990.

9 Bayles KA, Tomoeda CK: Functional Linguistic Communication Inventory. Austin, Pro-Ed, 1994

10 Gelinas I, Gauthier L, McIntyre M, Gautier S: Development of a functional measure for persons with Alzheimer's disease: the disability assessment for dementia. Am J Occup Ther 1999;53:471-481.

11 Loeb PA: Independent Living Scales. San Antonio, The Psychological Corporation, 1996.

12 Carvalho IAM, Bahia VS, Mansur LL: Functional communication ability infrontotemporal lobar degeneration and Alzheimer's disease. Dement Neuropsychol 2008;2:31-36.

13 Frattali C, Thompson C, Holland A, Wohl CB, Ferketic M: The American Speech-Language-Hearing Association Functional Assessment of Communication Skills for Adults (ASHA FACS). Rockville, American SpeechLanguage-Hearing Association, 1995.

14 Folstein MF, Folstein SE, McHugh PR: Mini-mental state. A practical method for grading the cognitive state of patients for the clinician. J Psychiatr Res 1975;12:189-198.

15 Morris JC: The Clinical Dementia Rating (CDR): current version and scoring rules. Neurology 1993;43:24122414.

16 Hughes J, Orange JB: Mapping functional communication measurements for traumatic brain injury to the WHO-ICF. Can J Speech Lang Pathol Audiol 2007;31:134-144.

17 Cieza A, Brockow T, Ewert T, Amman E, Kollerits B, Chatterji S, Ustün TB, Stucki G: Linking health-status measurements to the international classification of functioning, disability and health. J Rehabil Med 2002;34: 205-210.

18 Granberg S, Möller K, Skagerstrand A, Möller C, Danermark B: The ICF Core Sets for hearing loss: researcher perspective, Part II: linking outcome measures to the International Classification of Functioning, Disability and Health (ICF). Int J Audiol 2014;53:77-87.

19 Byrne K, Orange JB: Conceptualizing communication enhancement in dementia for family caregivers using the WHO-ICF framework. Adv Speech Lang Pathol 2005;7:187-202.

20 Threats TT, Worrall L: Classifying communication disability using the ICF. Adv Speech Lang Pathol 2004;6: 53-62.

21 Machado F: Quality of life and Alzheimer's disease: influence of participation at a rehabilitation center. Dement Neuropsychol 2009;3:241-247.

-22 Albert MS: Changes in cognition. Neurobiol Aging 2011;32(suppl 1):S58-S63.

23 Zientz J, Rackley A, Chapman SB, Hopper T, Mahendra N, Kim ES, et al: Evidence-based practice recommendations for dementia: educating caregivers on Alzheimer's disease and training communication strategies. J Med Speech Lang Pathol 2007; 15:liii-lxiv.

24 Robinson CM, Paukert A, Kraus-Schuman CA, Snow AL, Kunik ME, Wilson NL, Stanley MA: The involvement of multiple caregivers in cognitive-behavior therapy for anxiety in persons with dementia. Aging Ment Health 2011;15:291-298.

25 Kinsella K, Phillips DR: Global aging: the challenge of success. Popul Bull 2005;60:1-40.

-26 American Speech-Language-Hearing Association: The roles of speech-language pathologists working with individuals with dementia: position statement. Rockville, American Speech-Language-Hearing Association, 2005. 